\title{
Long-Term Follow-Up of 82 Cavernous Sinus Meningiomas Treated with Radiosurgery
}

\author{
Mari Pascual Gallego', Jose Samblas², Jose Carlos Bustos², \\ Jose Angel Gutierrez Diaz ${ }^{2}$, Marisa Gonzalez², Kita Sallabanda1,2* \\ ${ }^{1}$ Departament of Neurosurgery, Hospital Clínico San Carlos, Universidad Complutense de Madrid, Madrid, \\ España \\ ${ }^{2}$ Neuro-Oncology Unit, Hospital San Francisco de Asís-Grupo IMO, Madrid, España \\ Email: ${ }^{*}$ ksallabanda@grupoimo.com
}

Received 25 July 2014; revised 20 August 2014; accepted 14 September 2014

Copyright (C) 2014 by authors and Scientific Research Publishing Inc.

This work is licensed under the Creative Commons Attribution International License (CC BY).

http://creativecommons.org/licenses/by/4.0/

(c) (i) Open Access

\section{Abstract}

The cases of 82 patients with cavernous sinus meningioma (CSM) treated with Stereotactic Radiosurgery (SRS) at our institution from 1992 to 2005 were retrospectively reviewed. The mean follow-up time was 8.38 years. Patients' age ranged between 16 and 78 years (mean 51). There were 35 patients who had been operated before, and two of them had been treated with fractionated radiotherapy. Twenty-three from 35 patients were surgically intervened $(65.7 \%)$ and presented post-surgical morbidity. Only in 3 cases the surgery was considered complete. The patients were referred for SRS treatment due to having tumour remains or a tumour growth. The mean volume of the tumour was $17.96(+/-13.67) \mathrm{cm}^{3}$. All the patients had been treated with a Linear Accelerator (LINAC) using a high precision positioning and radiation system (SRS 2000) University of Florida. The clinical progress of the patients was assessed using pre- and post-SRS radiological imaging, post-surgical and pre-post-SRS morbidity and mortality. Tumour volume decreased significantly with $R S$ in 61 of 82 patients (74.4\%). The tumour volume remained stable 12 patients $(14.6 \%)$ and only in 9 patients $(11 \%)$ was there tumour growth after SRS. Of these, 5 required surgical intervention, and 7 of the 82 underwent SRS or another fractionated stereotactic radiotherapy after the RS. Morbidity due to the SRS was only seen in 14 out of the 82 patients treated with SRS, five of them recovered completely. SRS is a high precise and effective treatment with low morbidity, becoming more and more the option of choices in the treatment of cavernous sinus meningioma.

\section{Keywords}

Cavernous Sinus Meningioma, Radiosurgery, LINAC

\footnotetext{
${ }^{*}$ Corresponding author.
} 


\section{Introduction}

Cavernous sinus meningioma had often been considered inoperable. The development of microsurgery and cranial base surgery has led to a safer and more effective treatment, and their use has become a challenge for many neurosurgeons. Despite improvements in the techniques and neurosurgeon skills, gross-total resection is still associated with significant morbidity [1]-[4]. It has been well documented that these tumors may commonly invade bone, muscle, dura, dural sinuses [5], and even the carotid wall [6], being almost impossible one total removal. Until now, there is no consensus on the optimal management strategy for CS meningioma and these strategies are still in evolution. The main aim is to maintain or improve patient functionality [7]. Since the introduction of radiosurgery (RS) as an effective, high precision technique with minimal morbidity, and applicable to patients with a high surgical risk [8] [9], it has been well documented its effectiveness by several articles published in the literature [10]-[21].

The aim of the paper is to demonstrate that SRS is a high precise and effective treatment with low morbidity, becoming more and more the option of choice in the treatment of cavernous sinus meningioma.

\section{Materials and Methods}

The cases of 82 consecutive patients with CSM treated with Stereotactic Radiosurgery at the Department of Neurosurgery, Hospital San Francisco de Asís, Madrid, Spain, from 1992 to 2005 were retrospectively reviewed.

Histology was not required in the 45 patients (54.8\%) with high suspicion of CSM based on the imaging features that received SRS as first line therapy. Of the patients, 35 (42.7\%) had undergone surgery before SRS, and 2 (2.4\%) had received radiotherapy previous to SRS treatment. Three of the patients (3.7\%) had NF II. The total tumour volume ranged from $1.54 \mathrm{~cm}^{3}$ to $60 \mathrm{~cm}^{3}$ (median, $17.96 \mathrm{~cm}^{3}$ ).

The mean volume of the tumour was $12.29 \mathrm{~cm}^{3}$ for the SRS-alone group and $25.56 \mathrm{~cm}^{3}$ for the postoperative SRS group.

The punctuation in the KPS previous to SRS ranged from 60 to 100 (mean 80).

Thirty patients had no neurological deficit attributed to the CSM. However, only eight of them were completely asymptomatic. As shown in Table 1, 57 patients had functional deficit of cranial nerves, being the main neurological manifestation at time of the treatment eye movement disorders. There were 24 oculomotor palsy, 11 trochlear palsy, and 33 abducent nerve palsy. There were 28 patients with visual tract impairment. There were 28 patients with sensibility disturbances in V1, 24 in V2 and 16 in V3. Epilepsy was present in 6 of the patients $(0.07 \%)$.

\subsection{Treatment and Follow-Up}

In all cases, SRS was carried out using a linear accelerator with high precision positioning system and mechanical fixation of the tertiary collimator (SRS 200; University of Florida, Gainesville, FL), with 6-MV photons. To locate the lesion, magnetic resonance image (MRI) was performed, after which the stereotactic frame was placed under local anaesthesia for the planning CT phase. CT scan was obtained with fine axial cuts $(1 \mathrm{~mm})$ of the whole head. An image fusion program was used to delimit the target volume. Three-dimensional treatment plan-

Table 1. Previous sintomatology.

\begin{tabular}{ccc}
\hline Sintomatology & No of Patients & $\%$ \\
\hline II pc & 28 & $34.1 \%$ \\
III pc & 24 & $29.3 \%$ \\
IV pc & 11 & $13.4 \%$ \\
V1 pc & 28 & $34.1 \%$ \\
V2 pc & 24 & $29.3 \%$ \\
V3 pc & 16 & $19.5 \%$ \\
VI pc & 33 & $39 \%$ \\
Epilepsia & 6 & $7.3 \%$ \\
\hline
\end{tabular}


ing was made in all cases, using different planning units (Philips SRS 200 [Philips, Madison, WI], Brain Lab [Brain-Lab, Feldkirchen, Germany], Plato-Nucletron [Nucletron, Veenendaal, Netherlands] and ERGO-3D Line [3D-Linne Medical Systems, Milan, Italy]) during the period of study.

Dose planning was performed to cover the enhancing tumour as conformably as possible. A mean dose of $13.85 \mathrm{~Gy}$, median $14 \mathrm{~Gy}$, was prescribed to the $74.23 \%$ (range $50 \%-90 \%$ ) mean isodose, median $77.5 \%$. The number of collimators used varied from one to five: one was used in 21 cases; two were used in 42 cases; three in 13 cases; four in 5 cases and one was used only in one case. The maximum dose to adjacent radiosensitive structures, such as the optic chiasm or optic nerves, was calculated, never trespassing the tolerance dose of $8 \mathrm{~Gy}$, with a total cover of 50 (61\%) of the lesions. Nonetheless, the dural tail was always treated.

The mean follow-up time after SRS was 114 months, 8.38 years, (range 59 - 240; SD = 46.19). All the patients were followed up yearly with neurological examinations and contrast-enhanced MRIs at least for 58.68 months, with a mean follow up of 114.27 months. Tumour size was controlled by measuring the contrast-enhanced margin, in three standard MRI dimensions, before and after SRS.

\subsection{Statistical Analysis}

Progression free survival rates were calculated by the method of Kaplan and Meier [22] (Graphic 1). Tumour progression was considered as the radiological finding of an increase in size, and tumour control was defined when the tumour size remained stable or decreased during the imaging follow up studies. The results were analysed using the SPSS version 21 (SPSS INC., Chicago, IL). Continuous variables were compared with the student t-test. Nonparametric variables were compared by the chi-squared test.

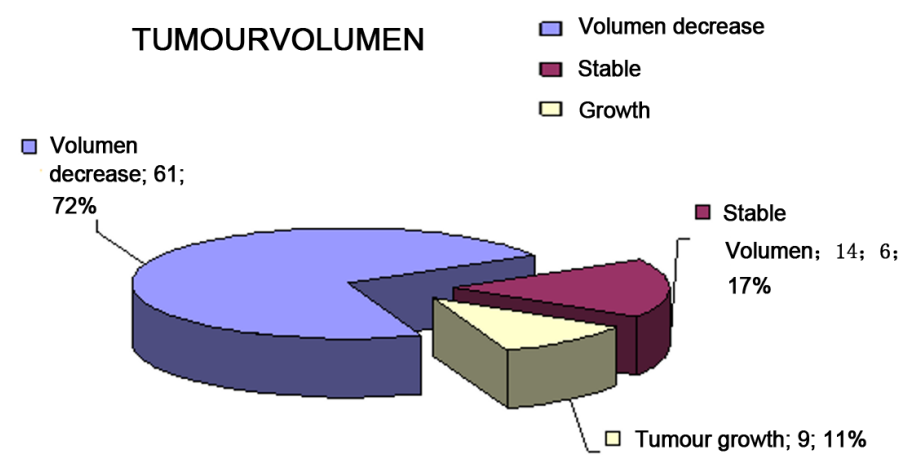

\section{Results}

Patients' age ranged between 16 and 78 years (mean 51), and seventy patients (85.4\%) were females.

The last follow up control rate was $89 \%$. Volume reduction was objectified in sixty-one patients (74.4\%), and volume remained stable in twelve patients (14.6\%). Nine tumours grew, 6 of them whose had been previously operated and none of them had received previous radiotherapy.

As shown in the following graphic, the 5-year progression-free survival (PFS) was 95\% and the 10-year PFS 84\% (Figure 1).

Only one patient died, due to complications after surgery of the meningioma (Garf 2 Clinical).

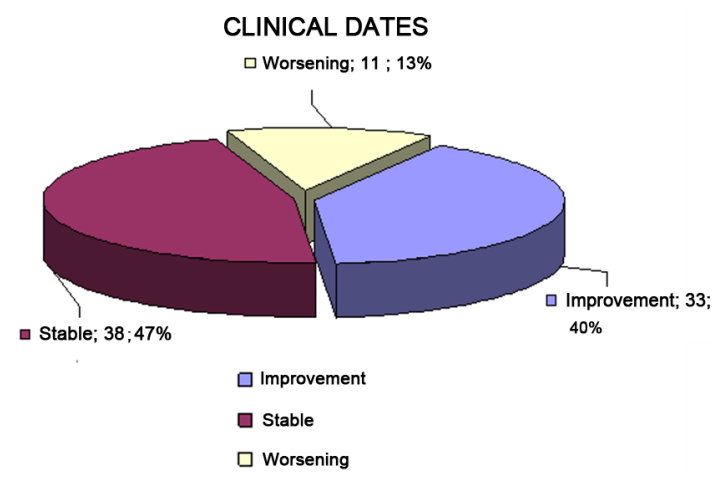


One variant analysis of prognostic factors was performed for PFS. No one of the analysed factors (age, sex, volume of the treated tumour, previous surgery or radiotherapy and the size of target coverage) showed any association with PFS. Five patients underwent surgical resection after RSR due to tumour progression after SRS.

Fifty-seven patients had cranial nerve deficits due to their cavernous sinus tumours, some of the presenting multiple neuropathies.

As shown in Table 2, the toxicity after SRS was low, and in some cases the patient improved it.

\section{Discussion}

Despite many studies that have been published until the moment, the optimal management of CSM still remains in debate.

Based on the published literature, surgery-related morbidity was higher than that for SRS, including either gross total and subtotal resection, and patients receiving SRS experienced lower rates of tumour recurrence compared with patients who underwent surgery alone [23]. Long-term studies of meningioma involving the cavernous sinus after surgery reported recurrence rates of $9.6 \%$ after "complete resection", and $15.2 \%$ after subtotal resection [24]. Recurrence rates in most studies published until the moment range from $9.6 \%$ to $25 \%$. [24] [25]

SRS has shown that, even when full coverage of the target was not possible, good outcomes in the treatment of patients with cavernous sinus meningioma can be achieved [11]. Recent studies [26] have shown progression free survival rates of $94 \%$ after 5 years and $86 \%$ at 8 years, with a median follow-up of 62 months. In the present study, PFS was $95 \%$ at 5 years and $84 \%$ at 10 years with a median follow-up of 100.66 months. It is

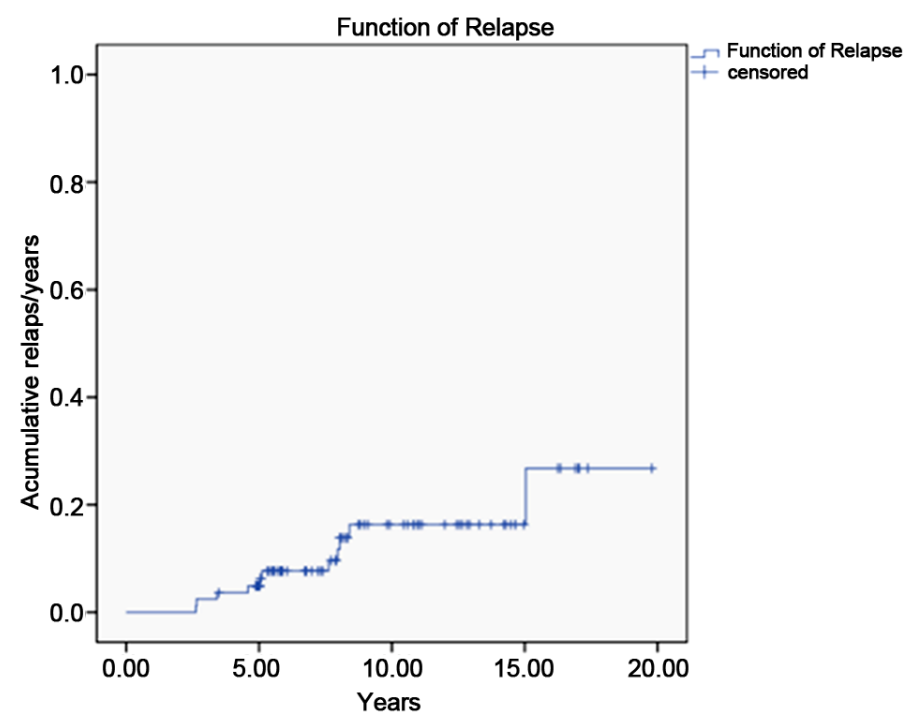

Figure 1. Kaplan meier curve: Progression-free survival.

Table 2. Toxicity after SRS (cranial nerve and hypofisis).

\begin{tabular}{ccc}
\hline Cranial & Toxicity & Improved \\
\hline II pc & $3(3.6 \%)$ & 0 \\
III pc & 0 & 0 \\
IV pc & 0 & 0 \\
V1 pc & $4(4.9 \%)$ & 0 \\
V2 pc & $5(6 \%)$ & 2 \\
V3 pc & $2(2.4 \%)$ & 0 \\
VI pc & $2(2.4 \%)$ & 0 \\
Hypofisis & $3(3.6 \%)$ & 2 \\
\hline
\end{tabular}


important to compare studies with a long follow-up, because it has been well documented that recurrence or progression may occur decades after surgical resection or radiation therapy [17] [27]-[29].

Sughrue et al. Concluded from a large meta-analysis published in 2010 [23] that purely intracavernous masses, without cofounding medical histories to suggest other pathology, can be controlled with SRS alone, potentially lowering morbidity and associated health care costs compared with aggressive resection. They also found data that seemed to suggest that SRS should be the therapeutic modality of choice for cavernous sinus meningioma, reserving surgery for cases involving large exofitic components or optic nerve compression.

With numerous studies published until the moment, and also supported by our data, we can affirm that early radiosurgery greatly increases the chance of improving cranial nerve deficits that are not surgically induced.

In the majority of studies revised, tumour margin doses ranged from 12 to $18 \mathrm{~Gy}$, with a mean of dose between 13 and 14 Gy. In our study the mean tumour margin dose was 13.9 Gy. With these doses we didn't experienced late complications such as internal carotid artery stenosis, late complications that have been documented in other series with higher tumour margin dose means (Pollock). Another question opened previously by Pollock et al. (Pollock) is that it is possible that Linac-based radiosurgery could have a lower rate of neurovascular complications compared to Gamma Knife radiosurgery secondary to greater dose homogeneity and lower maximum radiation doses within the dose plan. But, as they pointed out, more articles have detailed the results of Gamma Knife radiosurgery for cavernous sinus meningioma than Linac-based radiosurgery of cavernous sinus meningioma [10] [11] [20] [30] [31].

Larger tumor volume remains the primary factor associated with complications after single-fraction SRS of benign CSM despite advancements in SRS technique [32].

Despite the techniques, it is of note that tumour control rates have remained practically unchanged over time in spite of changes in quality of imaging, and radiosurgical dose [30]. Comparing the results previously published by our group for the treatment of cavernous sinus meningioma [11] with this study we can observe that they have improved, but the difference is not statistically significant. The 5-year PFS in the patients treated for CSM of the study published in 2002 was $92.5 \%$, and the 10 -year PFS $82.5 \%$. On the other hand, the 5-year PFS and the 10 -year PFS in the current study were $95 \%$ and $84 \%$ respectively.

The importance of the inclusion in the target of the dural tail to obtain better results has been previously highlighted by our group and in other publications [11] [33], and we have observed again better results in terms of PFS in the patients that it has been included in the target, with the limitation of a prospective study without randomized treatment plans.

\section{Conclusions}

The difficulty in performing a complete surgical resection and the associated morbidity has led to many neurosurgeons and patients to choose the treatment with SRS as the only and/or complementary treatment in cavernous sinus meningiomas. Long-term studies have demonstrated the efficacy, low morbidity and the accuracy of radiosurgical treatment, which is becoming the option of choice in the treatment of cavernous sinus meningiomas.

SRS is not only a complement of the surgical treatment, but frequently replaces it. Radiosurgery has become an integral management option for these lesions, either as an adjunct to surgery, or as a stand-alone treatment [8].

\section{References}

[1] Sekhar, L.N., Linskey, M.E., Sen, C.N. and Altschuler, E.M. (1991) Surgical Management of Lesions within the Cavernous Sinus. Clinical Neurosurgery, 37, 440-489.

[2] DeMonte, F., Smith, H.K. and Al-Mefty, O. (1994) Outcome of Aggressive Removal of Cavernous Sinus Meningiomas. Journal of Neurosurgery, 81, 245-251. http://dx.doi.org/10.3171/jns.1994.81.2.0245

[3] Dolenc, V.V., Kregar, T., Ferluga, M., Fettich, M. and Morina, A. (1987) Treatment of Tumors Invading the Cavernous Sinus. In: Dolenc, V.V., Ed., The Cavernous Sinus, Springer-Verlag, Wien, New York, 372-391.

[4] O’Sullivan, M.G., van Loveren, H.R. and Tew Jr., J.M. (1997) The Surgical Resectability of Meningiomas of the Cavernous Sinus. Neurosurgery, 40, 238-244. http://dx.doi.org/10.1097/00006123-199702000-00003

[5] Okazaki, H. and Scheithauer, B.W. (1988) Atlas of Neuropathology. London Gower Medical Publishing, New York, JB Lippincott, Philadelphia. 
[6] Shaffrey, M.E., Dolenc, V.V., Lanzino, G., Wolcott, W.P. and Shaffrey, C.I. (1999) Invasion of the Internal Carotid Artery by Cavernous Sinus Meningiomas. Surgical Neurology, 52, 167-171. http://dx.doi.org/10.1016/S0090-3019(99)00092-0

[7] Meningiomas: A Comprehensive Text M. Necmettin Pamir, Peter M. Black, and Rudolf Fahlbusch Chapter 34, 453-468 Copyright (C) 2010 by Saunders, an Imprint of Elsevier Inc. All Rights Reserved.

[8] Schmidek and Sweets Operative Neurosurgical Techniques: Indications, Methods and Results, Sixth Edition Alfredo Quiñones-Hinojosa Chapter 38, 451-467 Copyright (C) 2012, 2006, 2000, 1995, 1988, 1982 by Saunders, an Imprint of Elsevier Inc.

[9] Duma, C.M., Lunsford, L.D., Kondziolka, D., Harsh 4th, G.R. and Flickinger, J.C. (1993) Stereotactic Radiosurgery of Cavernous Sinus Meningiomas as an Addition or Alternative Tomicrosurgery. Neurosurgery, 32, 699-704. http://dx.doi.org/10.1227/00006123-199305000-00001

[10] Chang, S.D. and Adler Jr., J.R. (1997) Treatment of Cranial Base Meningiomas with Linear Accelerator Radiosurgery. Neurosurgery, 41, 1019-1025. http://dx.doi.org/10.1097/00006123-199711000-00003

[11] dos Santos, M.A., de Salcedo, J.B., Diaz, J.A.G., Calvo, F.A., Samblás, J., Marsiglia, H. and Sallabanda, K. (2011) Long-Term Outcomes of Stereotactic Radiosurgery for Treatment of Cavernous Sinus Meningiomas. International Journal of Radiation Oncology \& Biology \& Physics, 81, 1436-1441. http://dx.doi.org/10.1016/j.ijrobp.2010.07.2002

[12] Iwai, Y., Yamanaka, K. and Ishiguro, T. (2003) Gamma Knife Radiosurgery for the Treatment of Cavernous Sinus Meningiomas. Neurosurgery, 52, 517-524. http://dx.doi.org/10.1227/01.NEU.0000047814.18819.9F

[13] Lee, J.Y., Niranjan, A., McInerney, J., Kondziolka, D., Flickinger, J.C. and Lunsford, L.D. (2002) Stereotactic Radiosurgery Providing Long-Term Tumor Control of Cavernous Sinus Meningiomas. Journal of Neurosurgery, 97, 65-72. http://dx.doi.org/10.3171/jns.2002.97.1.0065

[14] Liščák, R., Šimonová, G., Vymazal, J., Janoušková, L. and Vladyka, V. (1999) Gamma Knife Radiosurgery of Meningiomas in the Cavernous Sinus Region. Acta Neurochirurgica (Wien), 141, 473-480. http://dx.doi.org/10.1007/s007010050327

[15] Morita, A., Coffey, R.J., Foote, R.L., Schiff, D. and Gorman, D. (1999) Risk of Injury to Cranial Nerves after Gamma Knife Radiosurgery for Skull Base Meningiomas: Experience in 88 Patients. Journal of Neurosurgery, 90, 42-49. http://dx.doi.org/10.3171/jns.1999.90.1.0042

[16] Nicolato, A., Foroni, R., Alessandrini, F., Bricolo, A. and Gerosa, M. (2002) Radiosurgical Treatment of Cavernous Sinus Meningiomas: Experience with 122 Treated Patients. Neurosurgery, 51, 1153-1161. http://dx.doi.org/10.1097/00006123-200211000-00009

[17] Pollock, B.E. and Stafford, S.L. (2005) Results of Stereotactic Radiosurgery for Patients with Imaging Defined Cavernous Sinus Meningiomas. International Journal of Radiation Oncology \& Biology \& Physics, 62, 1427-1431. http://dx.doi.org/10.1016/j.ijrobp.2004.12.067

[18] Roche, P.H., Régis, J., Dufour, H., Fournier, H.D., Delsanti, C., Pellet, W., Grisoli, F. and Peragut, J.C. (2000) Gamma Knife Radiosurgery in the Management of Cavernous Sinus Meningiomas. Journal of Neurosurgery, 93, 68-73.

[19] Shin, M., Kurita, H., Sasaki, T., Kawamoto, S., Tago, M., Kawahara, N., Morita, A., Ueki, K. and Kirino, T. (2001) Analysis of Treatment Outcome after Stereotactic Radiosurgery Forcavernous Sinus Meningiomas. Journal of Neurosurgery, 95, 435-439. http://dx.doi.org/10.3171/jns.2001.95.3.0435

[20] Spiegelmann, R., Nissim, O., Menhel, J., Alezra, D. and Pfeffer, M.R. (2002) Linear Accelerator Radiosurgery for Meningiomas in and around the Cavernous Sinus. Neurosurgery, 51, 1373-1380.

[21] Zeiler, F.A., McDonald, P.J., Kaufmann, A.M., Fewer, D., Butler, J., Schroeder, G. and West, M. (2012) Gamma Knife Radiosurgery of Cavernous Sinus Meningiomas: An Institutional Review. Canadian Journal of Neurological Sciences, 39, 757-762.

[22] Kaplan, E.L. and Meier, P. (1958) Nonparametric Estimation from Incomplete Observations. Journal of the American Statistical Association, 53, 457-481. http://dx.doi.org/10.1080/01621459.1958.10501452

[23] Sughrue, M.E., Rutkowski, M.J., Aranda, D., Barani, I.J., McDermott, M.W. and Parsa, A.T. (2010) Factors Affecting Outcome Following Treatment of Patients with Cavernous Sinus Meningiomas. Journal of Neurosurgery, 113, 10871092. http://dx.doi.org/10.3171/2010.3.JNS091807

[24] De Jesús, O., Sekhar, L.N., Parikh, H.K., Wright, D.C. and Wagner, D.P. (1996) Long-Term Follow-Up of Patients with Meningiomas Involving the Cavernous Sinus: Recurrence, Progression, and Quality of Life. Neurosurgery, 39, 915-919. http://dx.doi.org/10.1227/00006123-199611000-00005

[25] Cusimano, M.D., Sekhar, L.N., Sen, C.N., Pomonis, S., Wright, D.C., Biglan, A.W. and Jannetta, P.J. (1995) The Results of Surgery for Benign Tumors of the Cavernous Sinus. Neurosurgery, 37, 1-9. http://dx.doi.org/10.1227/00006123-199507000-00001

[26] Kano, H., Park, K.J., Kondziolka, D., Iyer, A., Liu, X., Tonetti, D., Flickinger, J.C. and Lunsford, L.D. (2013) Does 
Prior Microsurgery Improve or Worsen the Outcomes of Stereotactic Radiosurgery for Cavernous Sinus Meningiomas? Neurosurgery, 73, 401-410. http://dx.doi.org/10.1227/01.neu.0000431471.64289.3d

[27] Mathiesen, T., Lindquist, C., Kihlström, L. and Karlsson, B. (1996) Recurrence of Cranial Base Meningiomas. Neurosurgery, 39, 2-7. http://dx.doi.org/10.1136/jnnp.20.1.22

[28] Simpson, D. (1957) The Recurrence of Intracranial Meningiomas after Surgical Treatment. Journal of Neurology, Neurosurgery Psychiatry, 20, 22-39. http://dx.doi.org/10.1136/jnnp.20.1.22

[29] Tafford, S.L., Perry, A., Suman, V.J., Meyer, F.B., Scheithauer, B.W., Lohse, C.M. and Shaw, E.G. (1998) Primarily Resected Meningiomas: Outcome and Prognostic Factors in 581 Mayo Clinicpatients, 1978 through 1988. Mayo Clinic Proceedings, 73, 936-942. http://dx.doi.org/10.4065/73.10.936

[30] Spiegelmann, R., Cohen, Z.R., Nissim, O., Alezra, D. and Pfeffer, R. (2010) Cavernous Sinus Meningiomas: A Large LINAC Radiosurgery Series. Journal of Neuro-Oncology, 98, 195-202. http://dx.doi.org/10.1007/s11060-010-0173-1

[31] Kimball, M.M., Friedman, W.A., Foote, K.D., Bova, F.J. and Chi, YY. (2009) Linear Accelerator Radiosurgery for Cavernous Sinus Meningiomas. Stereotactic and Functional Neurosurgery, 87, 120-127. http://dx.doi.org/10.1159/000204910

[32] Pollock, B.E., Stafford, S.L., Link, M.J., Garces, Y.I. and Foote, R.L. (2013) Single-Fraction Radiosurgery of Benign Cavernous Sinus Meningiomas. Journal of Neurosurgery, 119, 675-682. http://dx.doi.org/10.3171/2013.5.JNS13206

[33] DiBiase, S.J., Kwok, Y., Yovino, S., Arena, C., Naqvi, S., Temple, R., Regine, W.F., Amin, P., Guo, C. and Chin, L.S. (2004) Factors Predicting Local Tumor Control after Gamma Knife Stereotactic Radiosurgery for Benign Intracranial Meningiomas. International Journal of Radiation Oncology \& Biology \& Physics, 60, 1515-1519. http://dx.doi.org/10.1016/j.ijrobp.2004.05.073 
Scientific Research Publishing (SCIRP) is one of the largest Open Access journal publishers. It is currently publishing more than 200 open access, online, peer-reviewed journals covering a wide range of academic disciplines. SCIRP serves the worldwide academic communities and contributes to the progress and application of science with its publication.

Other selected journals from SCIRP are listed as below. Submit your manuscript to us via either submit@scirp.org or Online Submission Portal.
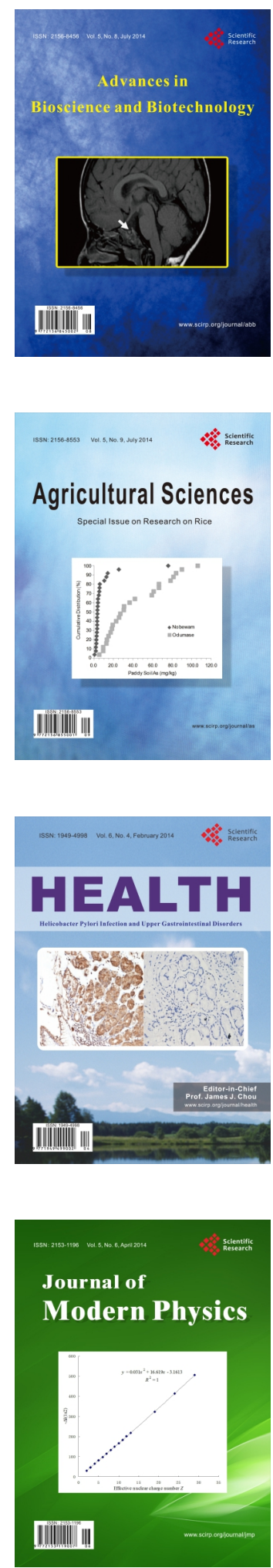
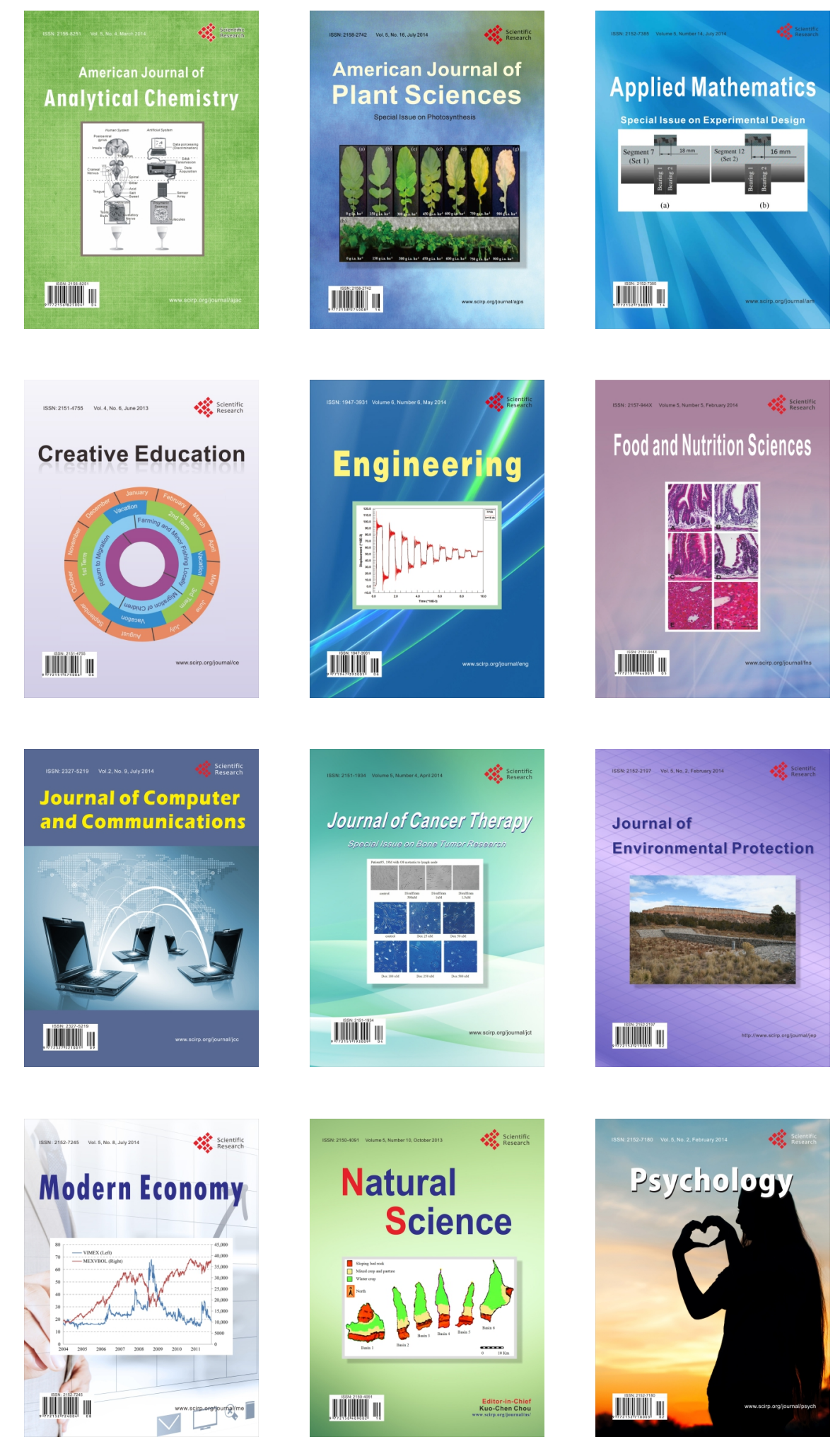